\title{
Projeto-piloto de teletrabalho para servidores técnicos da Universidade do Estado de Santa Catarina
}

\author{
Teleworking pilot project for technical workers of the University of the State of Santa \\ Catarina
}

\author{
Ana Luiza Leite ${ }^{1(\mathbb{D})}$, Dannyela da Cunha Lemos ${ }^{2}$ \\ ${ }^{1}$ Universidade do Estado de Santa Catarina (UDESC), Brasil, Doutoranda em Administração (UDESC), e-mail: \\ anaetiel@yahoo.com.br \\ 2 Universidade do Estado de Santa Catarina (UDESC), Brasil, Doutora em Administração (UDESC), professora do \\ departamento de Administração Empresarial (UDESC), e-mail: lemosda@gmail.com
}

\section{RESUMO}

Em consonância às demandas da globalização, flexibilidade e necessidade de isolamento social, o teletrabalho tem se mostrado uma nova alternativa laboral para gestores e profissionais. A pesquisa, baseada na literatura sobre teletrabalho, sobretudo, no trabalho realizado em casa, verificou a oportunidade de uma experimentação de teletrabalho por alguns servidores da UDESC. O objetivo da pesquisa é planejar, implementar e avaliar o projeto piloto de teletrabalho em uma instituição pública de ensino superior, por meio da estratégia de pesquisa-ação. A coleta de dados se deu por diferentes formas: questionário, documentos e reuniões. A análise dos dados foi realizada de acordo com a interpretação do referencial teórico, onde seguiram-se as categorias analíticas: cultura e normatização, infraestrutura, sensibilização, seleção, supervisão, condutores e barreiras, benefícios e fragilidades. O estudo busca contribuir para a literatura do teletrabalho por meio da apresentação do desenvolvimento dessa modalidade ao longo do tempo e suas nuances encontradas. $\mathrm{O}$ alinhamento da cultura organizacional e elaboração de normatização foram vistos como fundamentais para um projeto efetivo. A infraestrutura e sensibilização são necessárias para que ocorra o teletrabalho com geração de benefícios, assim como, a seleção alinhada ao perfil mais adequado e de forma voluntária. Por fim, verificou-se que há desvantagens e barreiras em menor escala do que benefícios e condutores.

Palavras-chave: Teletrabalho; Trabalho em casa; Instituição de Ensino Superior.

\begin{abstract}
In line with the demands of globalization, flexibility and the need for social isolation, teleworking has shown itself to be a new job alternative for managers and professionals. The research, based on the literature on telework, above all, on the home-based work, verified the opportunity of a telework experiment by some UDESC staff. The objective of the research is to plan, to implement, and to evaluate the teleworking pilot project in a public higher education institution, through the action research strategy. Data collection took place in different ways: questionnaire, documents, and meetings. Data analysis was performed according to the interpretation of the theoretical framework, which followed the analytical categories: culture and regulation, infrastructure, awareness, selection, supervision, drivers and barriers, benefits, and weaknesses. The study seeks to contribute to the teleworking literature by presenting the development of this modality over time and its nuances found. The alignment of the organizational culture and the elaboration of norms were fundamental for an effective project. Infrastructure and awareness are necessary for teleworking to generate benefits, as well as selection in line with the most appropriate profile and on a voluntary basis. Finally, it was found that there are disadvantages and barriers on a smaller scale than benefits and drivers.
\end{abstract}

Keywords: Teleworking; Home based work; Higher Education Institution. 


\section{INTRODUÇÃO}

Em consonância às demandas da globalização e flexibilidade, o teletrabalho tem se mostrado uma nova alternativa laboral para gestores e profissionais. A diminuição da necessidade da presença física devido às diversas tecnologias disponíveis possibilitou que o trabalho possa ser realizado em qualquer lugar. Com o advento do isolamento social ocasionado pela Covid-19, a modalidade de trabalho em casa ou home office tem sido utilizada por inúmeros profissionais, inclusive no setor público.

O teletrabalho tem sido alvo de estudos e promessas para melhoria da qualidade de vida no trabalho (HAU; TODESCAT, 2018), aumento da satisfação do trabalho (ABDULLAH; ISMAIL, 2012) e da produtividade (ILLEGEMS; VERBEKE; S'JEGERS，2001). O teletrabalho, pode, também, melhorar a imagem corporativa, como atividade ligada a responsabilidade social, que possibilite a inclusão social e digital de pessoas com deficiência (MELLO et al., 2014). Essa forma laboral se destaca como uma categoria de trabalho viável na administração pública brasileira, embora, dependente de incentivos das esferas governamentais e da iniciativa dos órgãos públicos que pretendem utilizar essa modalidade (DA SILVA, 2014).

A produção científica sobre o tema vem crescendo ao longo dos anos desde a década de 80, embora note-se a baixa quantidade de pesquisas em organizações públicas e estudos longitudinais (LEITE; LEMOS, 2019). Schroeder (2007) sugere que novos trabalhos de pesquisa sejam realizados sobre a questão do teletrabalho nas mais diversas Instituições de Ensino Superior (IES), a fim de que estas possam desenvolver práticas e políticas de implementação do teletrabalho.

Nesse sentido, buscou-se estudar o teletrabalho no contexto de uma IES pública, a Universidade do Estado de Santa Catarina (UDESC), em relação aos cargos técnicos administrativos. Ressalta-se que o corpo docente já possui flexibilidade de horário devido à natureza das suas atividades. O corpo técnico da instituição, por sua vez, não possui um programa institucionalizado como parte da estratégia de gestão de pessoas, mesmo possuindo atividades possíveis de se realizar em qualquer hora e em qualquer lugar.

A presente pesquisa verificou a oportunidade de uma experimentação de teletrabalho por alguns servidores da UDESC, realizando o acompanhamento e auferindo os resultados por meio de um processo de pesquisa-ação. À princípio, a implementação de um projeto-piloto de teletrabalho na instituição teria que ser desenvolvida com poucos participantes devido as limitações de tempo e pessoal. 
O objetivo geral da pesquisa é planejar, implementar e avaliar o projeto piloto de teletrabalho de uma instituição pública de ensino superior. Ou seja, foi utilizada a estratégia de pesquisa-ação para o desenvolvimento da pesquisa longitudinal na UDESC. Essa pesquisa ocorreu por meio de um projeto-piloto, que é anterior ao período de pandemia, pois já havia interesse por parte da UDESC nessa questão.

A criação de um programa de teletrabalho na universidade poderia possibilitar e acoplar as diretrizes do planejamento estratégico, no sentido de ser uma prática inovadora (NOHARA et al., 2010), de valorizar o colaborador e ser uma forma de retenção de pessoas, de otimizar o local de trabalho e equipamentos, de estabelecer e acompanhar de metas e objetivos (PÉREZ; SÁNCHEZ; CARNICER, 2002) e de propiciar maior autonomia (ROSENFIELD; DE ALVES, 2011).

\section{REFERENCIAL TEÓRICO}

O teletrabalho é definido como o trabalho realizado a partir de um local diferente do local de trabalho convencional, por meio do acesso aos sistemas de computador da organização com tecnologias da informação e comunicações (AGUILERA et al., 2016), verificado o horário de melhor qualidade de produção (HILL; FERRIS; MÄRTINSON, 2003) ou não. Isto é, o novo local de trabalho tem a possibilidade de ser em casa, onde utilizam-se os termos home office ou home-based work (AGUILERA et al., 2016).

Autores têm investigado etapas para o desenvolvimento do teletrabalho em organizações: quatro fases para Vargas e Osma (2013), cinco fases para Silva (2014) e três fases para Mross (2016). Contudo, apresentam as mesmas variáveis (planejamento, implementação e avaliação). O Quadro 1 foi disposto de forma a comparar as fases que foram segregadas nos autores que apresentam menos etapas para a implementação do teletrabalho.

Quadro 1 - Métodos de implementação de teletrabalho em organizações

\begin{tabular}{|l|l|l|}
\hline \multicolumn{1}{|c|}{ Vargas e Osma (2013) } & \multicolumn{1}{|c|}{ Silva (2014) } & \multicolumn{1}{|c|}{ Mross (2016) } \\
\hline $\begin{array}{l}\text { Diagnóstico (análise da do anteprojeto } \\
\text { propensão ao teletrabalho pela } \\
\text { organização) }\end{array}$ & $\begin{array}{l}\text { Adequação Preparação (criação do termo de } \\
\text { (levantamento de especificidades, } \\
\text { processos e análise SWOT) } \\
\text { abertura, artefatos e formulários de } \\
\text { controle, cartilhas de orientação e } \\
\text { capacitação, divulgação) }\end{array}$ \\
\hline $\begin{array}{l}\text { Design (planejamento do } \\
\text { programa de teletrabalho) }\end{array}$ & $\begin{array}{l}\text { Detalhamento estrutural (planejamento } \\
\text { detalhado - normatização, indicadores de } \\
\text { avaliação, estruturação do plano piloto, } \\
\text { divulgação e conscientização, seleção } \\
\text { dos colaboradores) }\end{array}$ & \\
\hline
\end{tabular}




\begin{tabular}{|c|c|c|}
\hline $\begin{array}{l}\text { Gestão (execução } \\
\text { teletrabalho) }\end{array}$ & $\begin{array}{l}\text { Anteprojeto (implementação e coleta de } \\
\text { dados para avaliação }\end{array}$ & $\begin{array}{l}\text { Execução (termos de participação, } \\
\text { planos de trabalho concluídos, } \\
\text { relatório parcial de avaliação) }\end{array}$ \\
\hline \multirow[t]{2}{*}{$\begin{array}{llr}\text { Avaliação } & \text { (análise } & \text { dos } \\
\text { resultados e } & \text { impactos } & \text { do } \\
\text { teletrabalho) } & & \end{array}$} & $\begin{array}{l}\text { Monitoramento e Controle (análise dos } \\
\text { dados coletados e realização de relatórios } \\
\text { para a tomada de decisão) }\end{array}$ & \multirow{2}{*}{$\begin{array}{lcc}\text { Conclusão } & \text { (relatório parcial de } \\
\text { avaliação, relatório final de } & \text { documentos } \\
\text { avaliação, } & \text { de } \\
\text { divulgação dos resultados, termo } \\
\text { de encerramento) }\end{array}$} \\
\hline & $\begin{array}{l}\text { Condições de Operação (replicação do } \\
\text { projeto-piloto para outras áreas da } \\
\text { instituição após comprovação de } \\
\text { sucesso) }\end{array}$ & \\
\hline
\end{tabular}

Fonte: elaborado pelas autoras (2020).

O método desenvolvido por Vargas e Osma (2013), ao destacar os obstáculos que o teletrabalho pode encontrar, distingue duas fases relacionadas ao planejamento dessa nova modalidade laboral. O método desenvolvido por Silva (2014), baseado em conceitos de gerenciamento de projetos, apresenta fases mais abrangentes para o planejamento e para a avaliação do teletrabalho nas esferas governamentais brasileiras. O método desenvolvido por Mross (2016) também foi desenvolvido na área pública e percebido como um projeto. Frisa-se a importância de adequar as etapas às características e peculiaridades de cada organização.

Nesta pesquisa, são abordadas características dos três métodos apresentados, seguindo uma abordagem simplificada de Mross (2016), por meio de três fases denominadas: (i) planejamento, (ii) implementação e (iii) avaliação.

\subsection{PLANEJAMENTO}

Inicialmente, no planejamento do teletrabalho, uma opção para o diagnóstico do contexto, seria a utilização da matriz SWOT, onde identificam-se oportunidades, ameaças, forças e fraquezas da organização em relação à aspectos do teletrabalho (VARGAS; OSMA, 2013; SILVA, 2014). Internamente, uma cultura de monitoramento periódico de gestão é necessária, e deve possuir iniciativas, indicadores, objetivos de longo prazo e metas intermediárias definidas que sejam suscetíveis de revisão, refinamento e feedback (PÉREZ; SÁNCHEZ; CARNICER, 2002; CONTRERAS; ROJAS, 2015). Ao o teletrabalho ser capaz de gerar insegurança por falta de regulamento (HAZAN; MORATO, 2018), a empresa possui a necessidade de instruir devidamente os empregados de realizar o trabalho remoto no que tange às medidas para evitar futuras doenças e acidentes de trabalho (BRASIL, 2017). Em contrapartida, o colaborador deve assinar um termo se responsabilizando pelas instruções fornecidas (BRASIL, 2017). 
O teletrabalho carece de uma equipe de apoio em relação ao suporte técnico, ao apoio organizacional, gerencial e à tarefa (BAYRAK, 2012). Como por exemplo, uma equipe coordenadora com a função de planejar e gerar soluções e suporte para os problemas que ocorram durante a experimentação (GOMES, 2002). Em relação ao suporte técnico, a adaptação tecnológica e investimento inicial devem ser verificados (PÉREZ; SÁNCHEZ; CARNICER, 2002), assim como, adequados ao teletrabalhador (FILARDI; CASTRO; ZANINI, 2020). Destaca-se que o teletrabalho pode ocasionar a transferência de custos (TREMBLAY; THOMSIN, 2012) de disponibilidade de equipamentos e recursos de trabalho ao teletrabalhador (ILLEGEMS; VERBEKE, 2004). A organização também precisa definir o nível e modo de segurança dos dados (VARGAS; OSMA, 2013) para não gerar a vulnerabilidade de dados internos (ILLEGEMS; VERBEKE; S'JEGERS, 2001).

Portanto, há a primordialidade de se desenvolver mecanismos que ajudem a balancear as atividades profissionais e a vida pessoal dos teletrabalhadores, dando maior atenção à infraestrutura, à tecnologia e ao suporte psicológico (FILARDI; CASTRO; ZANINI, 2020). Destaca-se que treinamentos e disponibilização de informações carecem ser feitos anteriormente ao voluntariado ao programa de teletrabalho da instituição (CARNEVAL, 2018). Esta preparação deve levar em consideração temas como: regras para participação; mecanismos de execução e controle das tarefas na modalidade; técnicas de planejamento e gerenciamento do tempo; infraestrutura necessária e manutenção; ergonomia do local de trabalho; saúde e segurança do trabalho e responsabilidades dos atores (MROSS, 2016; CARNEVAL, 2018).

A seleção dos teletrabalhadores pode ser realizada por meio das características dos indivíduos e das tarefas (TREMBLAY, 2002), desde que o servidor queira realizar o teletrabalho (CARNEVAL, 2018). As atividades mais individualizadas (ROCHA; AMADOR, 2018) e que já possuem a informação de forma precisa são mais relevantes para teletrabalhadores (BAYRAK, 2012). Pinto (2003) elenca oito atributos pessoais, que devem ser analisados em potenciais teletrabalhadores: (i) automotivação; (ii) autodisciplina; (iii) confiança; (iv) flexibilidade; (v) independência; (vi) bom senso; (vii) confiabilidade; (viii) adaptabilidade. Pessoas com um nível de ensino elevado possuem maior propensão à adoção do teletrabalho (ILLEGEMS; VERBEKE; S'JEGERS, 2001). A confiança a ser demonstrada nos teletrabalhadores não pode ser desconsiderada, para que eles possam agir com flexibilidade, o que pode levar a níveis mais altos de proatividade e adaptabilidade às mudanças (SOLÍS, 2017). Nesse sentido, um bom supervisor de teletrabalhador carece de habilidades cognitivas e 
afetivas (KATZ, 1987). Isto é, aprender a ser mentor remoto e gerir colaboradores para desenvolver relacionamentos em equipe com sinergia (KURLAND; COOPER, 2002).

Mross (2016) acredita que a análise do desempenho do teletrabalhador deve ser objetiva, baseada exclusivamente no resultado da tarefa, considerando o prazo de execução e a qualidade do trabalho. O teletrabalho agrega a necessidade de coordenação e sistemas de controle orientados para a produção e resultados (ILLEGEMS; VERBEKE; S'JEGERS, 2001). Destacase a possibilidade de introduzir ferramentas de gestão e controle que visem minimizar a falta de prática dos gestores em administrar pessoas nesse modelo de trabalho, buscando a isonomia no reconhecimento e na avaliação dos teletrabalhadores (FILARDI; CASTRO; ZANINI, 2020).

\subsection{IMPLEMENTAÇÃO E AVALIAÇÃO}

A implementação do teletrabalho pode ser marcada por barreiras e facilitadores ao longo do tempo. O Quadro 2 apresenta condutores e barreiras relacionados à divulgação do teletrabalho na organização e às tecnologias disponíveis:

Quadro 2-Condutores e barreiras

\begin{tabular}{|c|c|c|}
\hline CONDUTORES & ASPECTO & BARREIRAS \\
\hline $\begin{array}{l}\text { Falta de conhecimento do } \\
\text { conceito de teletrabalho } \\
\text { (ILLEGEMS; VERBEKE; } \\
\text { S'JEGERS, 2001) }\end{array}$ & DIVULGAÇÃO & $\begin{array}{c}\text { Preconceito por parte da sociedade, gestores e } \\
\text { servidores presenciais (MOKHTARIAN; SALOMON, } \\
\text { 1997). }\end{array}$ \\
\hline $\begin{array}{l}\text { Uso bem desenvolvido das } \\
\text { tecnologias (PÉREZ; } \\
\text { SÁNCHEZ; CARNICER, } \\
\text { 2002) }\end{array}$ & $\begin{array}{l}\text { TECNOLOGIAS } \\
\text { DISPONÍVEIS }\end{array}$ & $\begin{array}{c}\text { Adaptação tecnológica e investimento inicial (PÉREZ; } \\
\text { SÁNCHEZ; CARNICER, 2002) } \\
\text { Qualidade baixa das tecnologias de } \\
\text { comunicação em determinadas regiões } \\
\text { (CONTRERAS; ROJAS, 2015) }\end{array}$ \\
\hline
\end{tabular}

Fonte: elaborado pelas autoras (2020).

Desta forma, percebe-se que um mesmo aspecto pode se tornar uma barreira ou um facilitador da implementação do teletrabalho em uma organização. Do mesmo modo, o Quadro 3 apresenta aspectos que podem ser vistos como benefícios ou como dificuldades ao teletrabalhador: 
Quadro 3 - Benefícios e dificuldades

\begin{tabular}{|l|l|l|}
\hline \multicolumn{1}{|c|}{ BENEFÍCIOS } & ASPECTO & \multicolumn{1}{|c|}{ DIFICULDADES } \\
\hline $\begin{array}{l}\text { Reduz gastos referentes ao deslocamento } \\
\text { (HAZAN; MORATO, 2018), evita o estresse, } \\
\text { com deslocamento e melhora a utilização do } \\
\text { tempo (HAU; TODESCAT, 2018) }\end{array}$ & LOCALIZAÇÃO & $\begin{array}{l}\text { Ocasiona distanciamento de colegas } \\
\text { de trabalho a perda de trocas de } \\
\text { conhecimento } \\
\text { (ILLEGEMS; VERBEKE, 2004) }\end{array}$ \\
\hline $\begin{array}{l}\text { Maior concentração e menor número de } \\
\text { interrupções (TREMBLAY; THOMSIN, 2012) }\end{array}$ & TRABALHO de & $\begin{array}{l}\text { Dificuldade de controle de } \\
\text { performance } \\
\text { THOMSIN, 2012). }\end{array}$ \\
\hline $\begin{array}{l}\text { Melhoria entre o balanço vida/trabalho } \\
\text { (ILLEGEMS; VERBEKE; S'JEGERS, 2001). }\end{array}$ & FAMÍLIA & $\begin{array}{l}\text { Conflito familtrabalho } \\
\text { (SULLIVAN; LEWIS, 2001) }\end{array}$ \\
\hline
\end{tabular}

Fonte: elaborado pelas autoras (2020).

A mudança de localização do trabalho ocasiona benefícios pessoais, mas pode trazer dificuldades em confraternização com colegas de trabalho. Destaca-se que o teletrabalho também pode reduzir gastos referentes à alimentação e ao vestuário (TREMBLAY; THOMSIN, 2012). O trabalho também se altera em alguns aspectos e a relação com a família, que podem ser negativamente ou positivamente. Uma forma de buscar o balanço vida-trabalho seria o estabelecimento de mecanismos da organização para avaliar como são as condições de vida do colaborador antes de incluí-lo na modalidade de teletrabalho, com o intuito de prevenir a interferência da família no trabalho (SOLÍS, 2017).

\section{PROCEDIMENTOS METODOLÓGICOS}

A presente pesquisa se caracterizou com abordagem qualitativa, pois buscou realçar o modo como a experiência social foi criada e adquiriu significado (DENZIN; LINCOLN, 2006). Ou seja, pretendeu-se alcançar mudanças (THIOLLENT, 2009) na UDESC ao longo da pesquisa. Neste sentido, a pesquisa-ação apresentou-se como estratégia de pesquisa adequada ao objetivo de pesquisa, pois foi almejado testar a sistemática do teletrabalho por meio de processos colaborativos dos participantes (MACKE, 2006). Kurt Lewin, conhecido como fundador da dessa estratégia de pesquisa, foi um psicólogo que tinha como objetivo não somente desenvolver o conhecimento a respeito do comportamento humano, mas buscava também formas de intervir nesses comportamentos (LODI; THIOLLENT; SAUERBRONN, 2018).

O contexto da pesquisa é caracterizado por uma instituição de ensino superior pública do Estado de Santa Catarina. A UDESC atua nas áreas de ensino, pesquisa e extensão há mais de 50 anos. Dispõe de uma estrutura multicampi, com 12 unidades distribuídas em nove cidades 
do Estado de Santa Catarina, na Região Sul do Brasil, além de 32 polos de apoio presencial para o ensino a distância, em parceria com a Universidade Aberta do Brasil, do Ministério da Educação (UAB/MEC). A Universidade possui um Planejamento Estratégico denominado Plano 20, que, em 2010, passou por uma atualização para o período 2010-2030, principalmente com o incremento do diagnóstico estratégico. Com isso, a organização percebeu a necessidade de assumir a tecnologia da informação e comunicação como base pedagógica e administrativa (UDESC, 2010). Este planejamento foi utilizado na pesquisa documental do trabalho.

Destaca-se que as pesquisadoras possuem papel participativo no processo de mudança. Contudo, o principal ator é quem faz ou quem está efetivamente interessado na ação (THIOLLENT, 2009). Os principais servidores envolvidos no processo de mudança foram: PróReitor de Administração; Coordenadora de Desenvolvimento Humano e demais servidores do setor; Coordenadora de Recursos Humanos, Chefe de Setor de Direitos e Deveres e servidores do setor; Chefe de Setor de Remuneração e servidores do setor; Secretário de Tecnologia de Informação e Comunicação e servidores. Destaca-se que apenas quatro servidores do Setor de Apoio à Remuneração (SEREM) exerceram efetivamente o teletrabalho. Os demais servidores participaram do desenvolvimento do projeto para que fosse possível implementar o teletrabalho.

Para o desenvolvimento da pesquisa-ação utilizou-se como base as fases apresentadas por Tripp (2005): planejamento, implementação e avaliação. Esse conjunto de fases coincide com as propostas na literatura sobre teletrabalho, por Mross (2016): preparação, execução e conclusão, que também serviram de base para a pesquisa. São fases que podem ocorrer simultaneamente e estão em processo de constante mudança. A Figura 1 apresenta cada fase da pesquisa-ação no contexto de análise do processo de desenvolvimento do teletrabalho na UDESC e suas respectivas formas de coleta de dados. A coleta de dados ocorreu nas três etapas da pesquisa, de diferentes formas e com múltiplos atores. A seguir apresentam-se as técnicas utilizadas: 
Figura 1 - Coleta de dados realizada de acordo por fase na pesquisa-ação
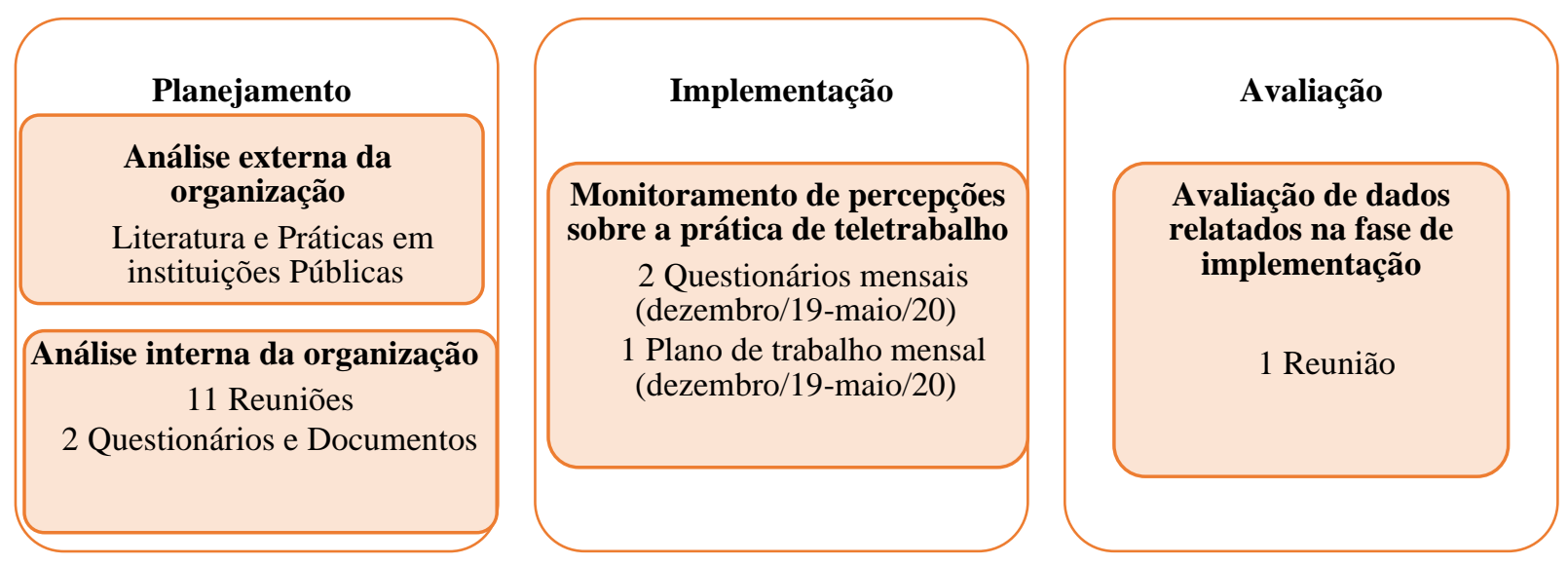

Fonte: elaborado pelas autoras (2020).

A fase de planejamento foi composta pela elaboração de planos de ação (TRIPP, 2005). A pesquisa de campo iniciou-se em 07/03/2019, onde foi realizada a proposta de estudo inicial sobre teletrabalho e busca por setor com condições propícias a esse modelo laboral. Além disso, dois questionários foram previamente estruturados para aplicação aos potenciais teletrabalhadores. Foram realizados com base em Hau e Todescat (2018), com objetivo de identificar o perfil dos servidores e sua propensão ao teletrabalho. Ainda, na fase do planejamento, foram realizadas 11 reuniões. Das quais, dez, foram entre as pesquisadoras e os servidores do Setor de Apoio a Remuneração (SEREM), onde ocorreu a apresentação e discussão da mensuração de produtividade, conscientização do gestor e servidores que iriam entrar em teletrabalho, orientações de saúde, ergonomia e segurança do trabalho. Destaca-se uma reunião realizada com a presença se servidores da área de recursos humanos e de tecnologia da informação da UDESC. Convencionou-se chamar de reuniões os encontros realizados com os grupos participantes do projeto, pois o termo seminário (THIOLLENT, 2009) requer, entre outras especificidades, a presença de especialistas do tema.

O início da implementação do projeto-piloto deu-se a partir de 01/12/2019, onde os servidores selecionados começaram a realizar o teletrabalho e se estendeu até o final de maio de 2020, totalizando seis meses. Para esta etapa, foram estruturados dois questionários de acompanhamento da experiência em teletrabalho. Os dois questionários foram de aplicação mensal (dezembro/2019 a maio/2020), um ao teletrabalhador, e outro, ao gestor. O questionário de aplicação mensal ao teletrabalhador foi desenvolvido com base em Carneval (2018), Hau e Todescat (2018) e Gomes (2002), enquanto o questionário do gestor foi desenvolvido com base em Lima (2018). Optou-se pelo questionário na fase de acompanhamento, para não ocupar 
muito tempo dos servidores em teletrabalho mensalmente. Outra ferramenta de controle durante a execução do projeto foi o plano de trabalho, uma planilha Excel estabelecida pela equipe em conjunto com as pesquisadoras, com o intuito de acompanhar o fluxo de trabalho e produtividade de cada servidor. Destaca-se que a comunicação foi frequente durante o processo, com trocas de e-mails e mensagens em grupo de WhatsApp.

A avaliação do projeto-piloto iniciou-se a partir de março de 2020, onde já havia dados suficientes para análise, e estendeu-se até junho de 2020. Na etapa de avaliação, ocorreu uma reunião próxima do término do projeto para discussão dos dados encontrados pelos questionários (THIOLLENT, 2009).

A análise dos dados foi realizada de acordo com a interpretação do referencial teórico, onde identificaram-se as seguintes categorias analíticas: cultura e normatização, infraestrutura, sensibilização, seleção, supervisão, condutores e barreiras, benefícios e fragilidades. Para a análise dos dados qualitativos foi adotada a análise de conteúdo categorial, onde utilizou-se procedimentos sistemáticos e objetivos de descrição do conteúdo das reuniões e questionários por meio de categorizações que permitiram a inferência de conhecimentos relativos às condições das variáveis identificadas (BARDIN, 2004).

\section{APRESENTAÇÃO E ANÁLISE DOS RESULTADOS}

Nesta seção são apresentadas as fases seguidas para concretização do desenvolvimento do projeto-piloto de teletrabalho na UDESC por meio da pesquisa-ação, classificada nos três blocos: (i) Planejamento, (ii) Implementação e (iii) Avaliação.

\subsection{PLANEJAMENTO}

\subsubsection{Cultura e normatização}

Para a análise da instituição, utilizaram-se os dados acoplados ao diagnóstico estratégico estabelecido pela utilização da matriz SWOT (VARGAS; OSMA, 2013; SILVA, 2014) do planejamento estratégico da UDESC (UDESC, 2010). Foram identificadas oportunidades e ameaças advindas do ambiente externo, e forças e fraquezas da organização em relação à aspectos do teletrabalho. 
A análise do ambiente interno da UDESC sinaliza não só um balanço social da única universidade estadual em solo catarinense, como, também, aponta seus pontos fracos e fortes para enfrentar os desafios futuros contidos no Plano 20 (UDESC, 2010). Há potencialidades de desenvolvimento e pontos fortes em diversos aspectos: recursos humanos, infraestrutura, eventos, extensão, pesquisa, pós-graduação e graduação. Em relação aos recursos humanos, destacam-se a capacitação do corpo técnico-administrativo e a implantação do Plano de Carreiras (UDESC, 2010).

A análise ambiental externa proporcionou a identificação de: (i) mudança nas relações de trabalho; (ii) modernização da infraestrutura econômica; (iii) crescimento da educação executiva ou de gestão; (iv) consolidação da cultura da avaliação; (v) educação permanente e de formatos diversificados. Estes aspectos se caracterizam como oportunidades ou ameaças, dependendo das ações realizadas pela UDESC referente a eles. Nesse sentido, percebe-se que o teletrabalho se encaixa como um propulsor de oportunidades destacadas pela UDESC. Em relação à cultura de avaliação, por exemplo, o teletrabalho pode contribuir com a introdução de monitoramento periódico de gestão por objetivos ou por resultados (PÉREZ; SÁNCHEZ; CARNICER, 2002; CONTRERAS; ROJAS, 2015).

A normatização do projeto-piloto no SEREM foi realizada por meio de um processo autorizado pelo Reitor para que não haja insegurança ou danos aos servidores participantes por falta de regulamento (HAZAN; MORATO, 2018).

\subsubsection{Infraestrutura}

As tecnologias disponíveis pela UDESC foram identificadas como adequadas (FILARDI; CASTRO; ZANINI, 2018), não sendo necessário investimentos (BAYRAK, 2012). Todos os servidores acreditam que possuem boa habilidade para utilizar o computador, softwares e sistemas necessários na execução de suas tarefas.

Três servidores possuem, em partes, recursos próprios necessários para realizar parte do trabalho em casa, como computadores, internet, mobiliários etc. Para um servidor faltava um computador. Quando perguntados sobre a disposição em arcar com aquisição de recursos para trabalhar em casa, em geral, os servidores não verificam como um ônus, pois acreditam que é um investimento que lhes agregará melhor qualidade de vida. Ao longo do projeto, não se percebeu a necessidade de investimentos em infraestrutura por parte dos participantes. À 
exceção do gestor, que entrou em teletrabalho a partir de março de 2020 e adquiriu um computador.

No sentido de não gerar custos à instituição, não foram fornecidos equipamentos aos servidores. Contudo, devido à falta de equipamentos e insegurança em investir em recursos necessários apenas para o tempo de pesquisa verificada pelos servidores, foram disponibilizados notebooks da UDESC como forma de empréstimo para a viabilidade da pesquisa.

Inicialmente, buscou-se averiguar a percepção do ambiente de trabalho disponibilizado pela UDESC, para posterior comparação ao ambiente criado em casa. A percepção geral dos servidores analisados em relação ao ambiente da UDESC foi classificada como regular. As principais vantagens do ambiente de trabalho disponibilizado pela UDESC são citadas: arcondicionado, local de trabalho com cadeira e mesa ergonômicos, interação com os colegas e contato com a chefia imediata. No que tange às desvantagens do ambiente de trabalho disponibilizado pela UDESC são citadas: climatização inadequada, contato forçado com os colegas, alto grau de interferência, luminosidade ruim, distância da residência e barulho.

\subsubsection{Sensibilização}

O teletrabalho envolve diretamente o teletrabalhador e gestor, mas não apenas ambos. Então, buscou-se criar uma equipe multidisciplinar (GOMES, 2002) para o projeto na UDESC. Por meio dessa formação de equipe, com especificidades em diferentes frentes, foi possível criar uma melhor orientação e dispor de ajuda qualificada ao teletrabalhador e gestor.

O gestor e teletrabalhador são os atores-chave que possuem a relação mais estreita e carecem ter um bom fluxo de informações e confiança (SOLÍS, 2017). Desta forma, o gestor de teletrabalhador tem a função de controlar e acompanhar a produtividade do teletrabalhador (definição de metas e ajustes); acompanhar a qualidade do trabalho; acordar formas de controle relativos à retirada, transporte, guarda e devolução de documentos físicos, se for o caso; possuir um olhar atento à saúde física e mental do servidor em teletrabalho; e, ainda, trabalhar a comunicação. Nesse sentido, um bom supervisor de teletrabalhador deve ter habilidades cognitivas e afetivas para gerir e desenvolver relacionamentos em equipe (KATZ, 1987; KURLAND; COOPER, 2002). Ademais, há relevância do suporte gerencial por meio de treinamento, e suporte nas tarefas que devem possuir maior frequência de acompanhamento (BAYRAK, 2012). 
O teletrabalhador teve a função de preencher um plano de trabalho de acordo com as tarefas realizadas; seguir as diretrizes especificadas pelos setores de apoio; manter a comunicação com o gestor; manter o nível de qualidade do trabalho; manter o nível de produtividade e manter o compartilhamento de dados a somente pessoas autorizadas. $\mathrm{O}$ gestor verifica o preenchimento do plano de trabalho do servidor e encaminha-o ao setor específico da UDESC, o qual computa a jornada de trabalho realizada nos dias de teletrabalho, pois nesses dias não há controle do ponto na instituição.

O setor relacionado às tecnologias na UDESC, também, possui um papel de apoio. Ele fornece orientações sobre equipamentos eletrônicos necessários (tipo de equipamento, tipo de versão, sistema operacional etc.); orientações sobre segurança de dados online; disponibilidade em auxiliar as configurações e dúvidas que aparecem.

O Recursos Humanos da UDESC também possui papel fundamental, principalmente em relação à preparação para entrada dos servidores nessa modalidade (MROSS, 2016; CARNEVAL, 2018), responder dúvidas e gerar orientações referentes aos aspectos ergonômicos, auxílio em questões sobre saúde no trabalho dos servidores, fornecimento de treinamentos e capacitações aos seus servidores.

\subsubsection{Seleção dos teletrabalhadores}

A seleção se estabeleceu, inicialmente, em busca de um setor que tivesse condições propícias ao teletrabalho. Encontrou-se no Setor de Apoio à Remuneração (SEREM) a oportunidade de lançar o projeto. Após isso, foi proposto ao chefe de setor do SEREM o projetopiloto, o qual foi bem recebido. Com uma análise do perfil pessoal de cada servidor e perfil das atividades destes foi possível perceber que havia viabilidade de ocasionar o regime do trabalho de forma remota (TREMBLAY, 2002).

As principais atribuições dos servidores do SEREM dizem respeito à remuneração dos servidores ao longo do tempo, sendo realizados a folha de pagamento mensal, gratificações, férias, promoção, progressão, aposentadoria, licenças, entre outras atividades. Em suma, o trabalho realizado no setor não traz a necessidade de comunicação entre os servidores para ser feito, é um trabalho mais individualizado e que exige concentração (ROCHA; AMADOR, 2018). O setor faz poucas reuniões e a necessidade de comunicação presencial entre eles é vista como exceção. O SEREM tem envolvimento com outros setores da instituição, contudo, o contato frequentemente é feito remotamente pelo sistema ou troca de e-mails. Percebe-se que a 
maioria das atividades não requer contato com outras pessoas (50\% a 90\%). As tarefas com necessidade de interação com outras pessoas de forma remota são estimadas em cerca de $10 \%$ a $20 \%$. Por fim, as tarefas que necessitam de interação presencial também são estimadas em $10 \%$ a $20 \%$.

Os servidores percebem que já possuem certa autonomia (ROSENFIELD; DE ALVES, 2011) para executar suas tarefas sozinhos. Além disso, concordam que possuem informações suficientes para a realização de suas tarefas (BAYRAK, 2012). O atendimento ao público não é visto como parte das tarefas de dois servidores, e para outros dois servidores, esse atendimento é mais recorrente.

Os quatro servidores do setor foram solícitos e propensos ao teletrabalho (CARNEVAL, 2018). Notam-se duas pessoas do sexo masculino e três do feminino. Quatro servidores se encaixam na faixa etária de 35 a 45 anos, e um servidor de 55 a 65 anos. Três servidores estão ocupando o cargo há mais de cinco anos enquanto dois servidores, há dois anos ou menos. Observa-se que todos estão há bastante tempo da instituição, sendo no mínimo por 8 anos e máximo de 25 anos. Destaca-se que apenas um servidor trabalha no setor todo o tempo em que está na instituição, enquanto todos os outros, trabalharam em diferentes setores antes de ocupar o cargo no SEREM. Sobre a formação acadêmica verifica-se que todos possuem Pós-Graduação completa, inferindo alto nível educacional (ILLEGEMS; VERBEKE; S’JEGERS, 2001), sendo três no campo da administração, um em ciências contábeis e um em pedagogia. No que tange a localização do domicílio, dois servidores moram relativamente perto da instituição (menos de $2 \mathrm{~km}$ ), um servidor há 7,5 km, e outros dois, entre $15 \mathrm{~km}$ e $21 \mathrm{~km}$.

Em relação ao perfil de personalidade, foram abordadas questões referentes às características pessoais que seriam importantes ao teletrabalhador (PINTO, 2003). Todos os servidores acreditam que são capazes de se adequar às novas circunstâncias, à abertura de conhecimentos e que têm capacidade de tomar decisões por conta própria de forma responsiva. Entre outras características mapeadas como propícias ao teletrabalho, infere-se que os colaboradores possuem perfis adequados ao teletrabalho de acordo com Pinto (2003).

Todos os servidores possuem um ambiente agradável em casa para trabalhar, sem responsabilidade de cuidar de outras pessoas e acesso à internet. Quando questionados sobre a motivação em participar do projeto piloto de teletrabalho, dois servidores acreditam que seria uma nova experiência e desafio profissional. Um servidor citou os benefícios que acredita conseguir com o teletrabalho e a contribuição para a realização dessa modalidade laboral na 
UDESC. Outro servidor informa: "Contribuir com um projeto de pesquisa científica que pode aperfeiçoar e ampliar as possibilidades de trabalho na Instituição".

\subsubsection{Supervisão e avaliação}

O controle das atividades exercidas pelos servidores passou a ser feito por resultados, ou seja, a análise do desempenho do teletrabalhador foi baseada exclusivamente no resultado da tarefa, considerando o prazo de execução e a qualidade do trabalho (MROSS). Foram realizadas três reuniões para definição e melhoria do plano de trabalho. A partir do final de julho até final de outubro de 2019, os servidores passaram a computar em uma planilha simples, suas atividades exercidas e tempo gasto. Em novembro de 2019, foram compilados os dados e encontradas médias de tempo gasto em cada atividade. Em seguida, foi realizada uma reunião com todos do setor, para discussão de cada tarefa, e a partir da verificação de tempo foram criados parâmetros de complexidade para cada atividade. Além disso, diversas atividades foram desmembradas em outras, devido a diferença de complexidade. Nesta reunião, também, foram discutidas as formas de contabilização e realização do plano de trabalho, para que ficasse mais simples o preenchimento pelos potenciais teletrabalhadores. Desta forma, houve a criação de uma planilha Excel mais elaborada com pesos de complexidade. Assim, diariamente os servidores selecionavam as atividades feitas e anotavam a quantidade. Ao final, geraram-se pontuações, com a multiplicação dos pesos de complexidade e quantidade de atividades despendidas.

Esse plano de trabalho foi operacionalizado pelas pesquisadoras com o apoio de professores e ideias dos teletrabalhadores e gestor. Houve, ainda, uma última reunião com todos os servidores do SEREM, onde foi repassado o preenchimento da planilha de produtividade, sanadas as dúvidas e verificado o possível início do teletrabalho.

\subsection{IMPLEMENTAÇÃO}

A intervenção da pesquisa se constituiu em implementar rotinas de trabalho remoto no cotidiano dos servidores do SEREM com ferramentas internas de controle, não representando custo significativo para a Administração. A duração do projeto foi de seis meses (dezembro de 2019 a maio de 2020), compreendendo o período de intervenção - que corresponde à prática da modalidade de teletrabalho na unidade. 
Iniciou-se o projeto-piloto de teletrabalho no começo do mês de dezembro, com cada servidor realizando o teletrabalho um dia por semana, ou seja, modalidade parcial (AGUILERA et al., 2016). O gestor, não entrou em teletrabalho também, pois acreditava-se que para uma primeira experiência, seria mais adequado ele continuar no trabalho presencial. Contudo, a partir de 17 de março de 2020 até final de maio de 2020, em virtude do isolamento social provocado pela pandemia da Covid-19, os servidores realizaram o trabalho remoto totalmente à distância, incluindo o gestor. Ou seja, inicialmente a aderência e periodicidade foi escolhida pelos gestores e servidores, mas com a necessidade de isolamento social houve a obrigatoriedade de teletrabalho integral. O projeto piloto ocorreu por esses seis meses com o intuito de acompanhar a experiência dos servidores e detectar problemas e facilidades ocorridas.

Como definido no planejamento, em relação à qualidade do trabalho apresentada pelos teletrabalhadores, o gestor percebeu que continuou satisfatória ao longo do período de teletrabalho, tanto uma vez por semana, como em todos os dias. Ou seja, "mantiveram o nível de trabalho desenvolvido quando estão trabalhando de forma presencial" (Gestor). Do mesmo modo, o gestor teve a percepção da manutenção da produtividade dos colaboradores por meio do controle de atividades ocasionado pelo plano de trabalho. Inicialmente, almejava-se a construção de uma pontuação para parâmetro de metas diárias e mensais aos servidores. Entretanto, grande parte das atividades do setor é realizada por demanda, o que dificulta a padronização mensal. Como verificou-se muita discrepância nas pontuações finais obtidas, não se gerou metas de produtividade. Desta forma, o plano de trabalho serviu para controle das atividades, ao invés de um instrumento para proposição de metas. Destaca-se, ainda, que a demanda é diferente entre os próprios servidores e as atividades que costumam desempenhar.

Em relação a satisfação profissional e qualidade de vida no primeiro trimestre, três servidores a avaliaram como satisfatória, enquanto um servidor classificou como regular. Identifica-se que apenas um servidor teve um aumento de qualidade de vida e outro de satisfação profissional em relação à quando trabalhavam apenas presencialmente, como era esperado pela literatura (HAU; TODESCAT, 2018; ABDULLAH; ISMAIL, 2012). Os demais mantiveram-nas.

No primeiro trimestre, a interação com as pessoas do setor SEREM continuou a mesma de acordo com todos os servidores, assim como, a interação com as pessoas de outros setores da instituição na modalidade parcial. Isso se deve ao fato de os servidores realizarem o teletrabalho apenas um dia por semana, estando os outros dias de forma presencial na UDESC. Contudo, na modalidade integral, três servidores sentiram que a interação passou a ser mais 
baixa do que antes a com as pessoas de outros setores da instituição. Apenas um servidor não sentiu alteração no nível de interação.

Em relação ao ambiente de trabalho remoto em suas respectivas residências os servidores o avaliaram como sendo agradável. Em relação à jornada de trabalho, todos foram orientados a continuar o horário padrão da instituição (das 13:00 as 19:00) não sendo considerado o horário mais produtivo de cada servidor (HILL; FERRIS; MÄRTINSON, 2003). Três servidores sentiram que trabalham o mesmo que a jornada padrão, enquanto um servidor sentiu que trabalhou um pouco mais que a jornada padrão durante o teletrabalho.

Em suma, os servidores têm conseguido separar suas atividades profissionais das atividades domésticas e distrações da família (SOLÍS, 2017), reservando horas de lazer fora do horário de trabalho. Em relação às atividades domésticas percebem-se algumas alterações na modalidade integral: "Agora, em tempos de quarentena, nem sempre consigo separar as atividades profissionais das atividades domésticas, já as distrações da família consigo separar" (Servidor 4); "Em virtude do isolamento social desde o dia 17, por estar 24h/dia em casa, quando já finalizei as atividades de trabalho eu faço pequenas e rápidas tarefas domésticas, intercalando sempre com verificação de e-mail, WhatsApp e SGPE.” (Servidor 3). Observa-se, que ao estarem o dia todo em casa, trabalhando integralmente à distância, surgem mais ocorrências de realização de tarefas domésticas.

Em relação à percepção de preparação para entrar no teletrabalho integral, os servidores do SEREM, que já estavam praticando uma vez na semana, se sentiram mais preparados em relação aos demais colegas que nunca haviam usufruído dessa modalidade. Desta forma, o projeto-piloto, iniciado em dezembro, auxiliou esses servidores a estarem mais preparados para a mudança repentina ao teletrabalho integral ocasionada pela necessidade de isolamento social.

\subsubsection{Condutores e barreiras percebidos}

Ao longo da execução do projeto-piloto foram encontrados condutores ao teletrabalho. Inicialmente, o apoio do Reitor ao permitir a sua realização, o apoio dos diversos setores envolvidos para a implementação desse trabalho na instituição e a disponibilidade dos servidores do SEREM em exercer o teletrabalho.

Não foi percebido preconceito por parte de outros servidores da UDESC (MOKHTARIAN; SALOMON, 1997): “Os colegas de sala estão cientes e compreensivos com o estudo e os dias em que cada um dos trabalhadores do SEREM está em teletrabalho" (Gestor); 
"Muitos elogiaram a disponibilidade da UDESC em permitir a nossa participação na pesquisa. Alguns até comentaram que gostariam também de poder participar” (Servidor 2). Ademais, em virtude da quarentena, demais servidores da UDESC, os quais não integram a pesquisa, começaram a trabalhar remotamente de suas casas passando a compreender melhor essa nova modalidade de trabalho.

As tecnologias da informação e comunicação também foram condutoras para implementação do teletrabalho (PÉREZ; SÁNCHEZ; CARNICER, 2002). Foi disponibilizado uma máquina virtual em que os teletrabalhadores têm acesso aos arquivos utilizados no SEREM e se manteve os empréstimos dos computadores pela UDESC para uso exclusivo dos servidores.

A repentina necessidade de as pessoas terem que trabalhar em casa, devido à pandemia da Covid-19, trouxe maior visibilidade e interesse ao tema, divulgando seu conceito (ILLEGEMS; VERBEKE; S'JEGERS, 2001). Isso torna-se um condutor à pesquisa e à implementação dessa modalidade laboral, que pode obter mais adeptos: “Apenas considero que será interessante para o trabalho das pesquisadoras esse período intensivo de teletrabalho em virtude da pandemia" (Servidor 3); "Muito bom o projeto, especialmente agora com a propagação da epidemia no mundo" (Servidor 5).

As barreiras encontradas durante a implementação do teletrabalho, por sua vez, foram poucas em relação aos facilitadores. Foi observado preconceito familiar pelo servidor 4 (HAU; TODESCAT, 2018), sendo que "alguns comentaram que é uma forma de precarização, ainda mais, do serviço público" (Servidor 4). Também, percebeu-se a falta de coordenação e sistemas de controle orientados para a produção e resultados (ILLEGEMS; VERBEKE; S'JEGERS, 2001). Outra barreira foi a escassez de profissionais na área da saúde no corpo de servidores da UDESC. O servidor 4 solicitou a possibilidade de disponibilizar profissionais da área da ajuda (do próprio quadro da UDESC): psicólogo, assistente social, coach e fisioterapeuta para acompanhar, avaliar e orientar os servidores em teletrabalho.

\subsection{AVALIAÇÃO}

Nesta seção são apresentadas as considerações finais sobre a experiência do projetopiloto. Avaliam-se os resultados positivos e negativos obtidos com a implementação e ajustes realizados durante o projeto-piloto de teletrabalho no SEREM.

Em relação aos benefícios profissionais esperados e alcançados ao entrar nessa modalidade de trabalho, o mais evidenciado foi o fato de evitar o estresse, principalmente com 
deslocamento (HAU; TODESCAT, 2018). Aspectos como maior concentração e menor número de interrupções (TREMBLAY; THOMSIN, 2012) também foram benefícios esperados e alcançados para os servidores: "Percebi que mais rápido é analisado os processos, com menos dispersões. Em algumas situações de dificuldades foi fácil encontrar a solução no sistema sem precisar perguntar ao coordenador" (Servidor 2).

Em relação aos benefícios esperados em nível individual o que se destaca é a melhoria na utilização do tempo (HAU; TODESCAT, 2018):

\footnotetext{
Ter mais tempo livre de manhã por não ter que se arrumar e deslocar para o trabalho; maior concentração por não ter conversas paralelas (moro sozinha). O silêncio que favorece bastante a minha concentração, e o ganho de tempo em não precisar se arrumar e deslocar para a UDESC (Servidor 3).
}

Os três servidores que residem com mais pessoas perceberam melhoria entre o balanço vida/trabalho como esperavam (ILLEGEMS; VERBEKE; S'JEGERS, 2001). A redução com gastos referentes ao deslocamento (HAZAN; MORATO, 2018), à alimentação e ao vestuário (TREMBLAY; THOMSIN, 2012) foram percebidas em maior escala na modalidade integral.

Os desafios que os servidores acreditam encontrar nessa modalidade laboral também foram analisados previamente. Dois servidores, inicialmente, apontaram ressalvas sobre essa nova modalidade de trabalho em relação ao potencial distanciamento de colegas de trabalho, perda de trocas de conhecimento entre os colegas informalmente (ILLEGEMS; VERBEKE, 2004) e dificuldade em tirar dúvidas. Essas fragilidades acabaram sendo sentidas por todos os servidores.

A comunicação com chefia e colegas durante o teletrabalho ocorreu por meio de WhatsApp. Contudo, "quando estou na UDESC falo pessoalmente então a resposta é mais rápida. A demora na resposta ou a falha de interpretação na comunicação escrita gera um pouco de ansiedade" (Servidor 3). Como a comunicação tem sido estabelecida, na maioria das vezes, por grupo de WhatsApp, para delegar atividades individuais, o servidor 4 sugeriu que quando a comunicação for direcionada a um único servidor, utilize-se a comunicação individual (via WhatsApp, e-mail ou algum outro meio que possa ser sugerido), "pois isso facilita no foco e concentração" (Servidor 4).

Em relação à mensuração de produtividade, esperava-se ter que trabalhar mais devido ao controle de produção e ter problemas com o controle de produção/horário. Contudo, apenas uma dificuldade se referiu ao "fato de lembrar de preencher a planilha de tudo que se faz" 
(Servidor 5), ou seja, dificuldade de controle de performance (TREMBLAY; THOMSIN, 2012). Os servidores acreditam ser importante esse controle de atividades e em sua continuidade mesmo em trabalho presencial. Pois foi verificado pelos servidores que ajuda a controlar e organizar o que está sendo realizado.

Os servidores já esperavam ter problemas com equipamentos e softwares, as quais foram a maioria das dificuldades enfrentadas. Referente às tecnologias da informação, houve alguns transtornos quanto o acesso VPN, acesso ao I (pasta compartilhada) e rapidez nas conexões. Nos últimos meses da experiência, em virtude da atual situação de saúde caótica que se vive, houve um aumento no número de usuários do teletrabalho sobrecarregando as redes (CONTRERAS; ROJAS, 2015). Em consequência houve queda do sistema e queda da internet em determinados locais, prejudicando os andamentos dos serviços (Servidor 5 e Gestor). Também, houve dificuldades relacionadas à ergonomia devido a tecnologia e equipamentos utilizados. "O fato de, em casa, utilizar notebook e não desktop, não possuir 2 monitores, nem mesa e cadeira ergonômicas, dificulta um pouco" (Servidor 3).

\section{CONSIDERAÇÕES FINAIS}

O objetivo geral da pesquisa foi planejar, implementar e avaliar o projeto piloto de teletrabalho de uma instituição pública de ensino superior ao longo do tempo. Mediante um estudo científico com estratégia de pesquisa-ação foi possível identificar o processo de desenvolvimento do projeto-piloto em uma universidade.

O estudo busca contribuir para a literatura do teletrabalho por meio da apresentação do desenvolvimento dessa modalidade ao longo do tempo e suas nuances encontradas. $\mathrm{O}$ planejamento dessa modalidade torna-se fundamental para a posterior implementação adequada. Ou seja, a organização deve possuir uma cultura alinhada ao que o teletrabalho transmite, uma normatização adequada, infraestrutura e sensibilização verificadas e realizadas, seleção de profissionais e tarefas adequadas e métodos de avaliação previamente mapeados. A implementação do teletrabalho, acompanhada por seis meses na instituição, trouxe reflexões interessantes. Por exemplo, a maioria dos servidores não reportaram melhoria na qualidade de vida e satisfação profissional. Ademais, não foi sentida resistência de servidores, como era previsto na literatura. Isto, pode ter ocorrido devido ao projeto envolver poucos servidores e que já tinham a propensão em experimentar esse tipo de trabalho. Durante a avaliação, 
percebeu-se que o teletrabalho em modalidade integral intensifica alguns benefícios, mas, também, dificuldades.

A escolha pela pesquisa-ação apresentou a possibilidade de coletar informações originais, em situações e atores no mundo real, a efetivação de conhecimentos teóricos, obtida da interação entre pesquisador e servidores da organização, a geração de regras práticas, na resolução de problemas e planejamento de ações e os resultados e ensinamentos positivos e negativos em relação à prática do teletrabalho.

Devido ao escopo de tempo e recursos, a presente pesquisa possui certas limitações. Não se constituíram como ações da implementação do teletrabalho no SEREM: (i) mensuração da economia de custos para a administração resultante da implantação da prática do teletrabalho; (ii) avaliação da viabilidade de implantação da modalidade de teletrabalho em outras áreas da instituição; (iii) utilização da prática do teletrabalho em tarefas cujos resultados não possam ser objetivamente avaliados. Outro ponto a considerar é o fato de a pesquisa ser abrangente, isto é, detalhar diversos aspectos em relação ao teletrabalho. Dessa forma, os aspectos não são analisados e refletidos tão profundamente caso fossem realizados de forma separada.

Fica proposto a continuidade de estudos sobre o tema, principalmente, de forma longeva. A pesquisa realizada verificou a implementação do teletrabalho por seis meses, e já identificou mudanças no ambiente ao longo do tempo. Com uma amostra e um horizonte temporal maior, pode ser possível identificar importantes informações sobre o desenvolvimento e impacto do teletrabalho no decorrer do tempo nas organizações.

\section{REFERÊNCIAS}

ABDULLAH, H.; ISMAIL, N. Quality of work and life balance in teleworking. International Business Management, v. 6, n. 2, p. 119-130, 2012.

AGUILERA, A., et al. Home-based telework in France: Characteristics, barriers and perspectives. Transportation Research Part A: Policy and Practice, v. 92, p. 1-11, 2016.

BARDIN, L. Análise de Conteúdo. 4 ed. Rev. Atual. Lisboa: 2004.

BAYRAK, T. IT support services for telecommuting workforce. Telematics and informatics, v. 29, n. 3, p. 286-293, 2012.

BRASIL. Lei n. 13.467, de 13 de julho de 2017. Altera a Consolidação das Leis do Trabalho (CLT), aprovada pelo Decreto-Lei no 5.452, de 1 de maio de 1943, e as Leis nos 6.019, de 3 de janeiro de 1974, 8.036, de 11 de maio de 1990, e 8.212, de 24 de julho de 1991, a fim de adequar a legislação às novas relações de trabalho. Brasília, 2017. Disponível em: 
http://www.planalto.gov.br/ccivil_03/_ato2015-2018/2017/lei/113467.htm. Acesso em: 09 jun. 2019.

CARNEVAL, P. P. L. Teletrabalho na administração pública: desenvolvimento de método de identificação de tarefas teletrabalháveis. 2018. Dissertação (Mestrado em Sistemas de Gestão) - Universidade Federal Fluminense, Rio de Janeiro, 2018.

CONTRERAS, O. E.; ROJAS, I. R. Teleworking and business sustainability. A reflection from the Human Resource Management in Colombia. Suma de Negócios, v. 6, n. 13, p. 74$83,2015$.

DA SILVA, J. A. Flexibilidad y teletrabajo: un estudio bibliométrico sobre la producción científica. Perspectivas em Ciência da Informação, v. 19, n. 2, p. 159-173, 2014.

DENZIN, N. K; LINCOLN, Y. S. O planejamento da pesquisa qualitativa: teorias e abordagens. 2.ed. Porto Alegre: Artmed, 2006.

FILARDI, F.; CASTRO, R. M. P. D.; ZANINI, M. T. F. Vantagens e desvantagens do teletrabalho na administração pública: análise das experiências do Serpro e da Receita Federal. Cad. EBAPE.BR, Rio de Janeiro, v. 18, n. 1, p. 28-46, 2020.

GOMES, M. H. T. S. Análise da adoção do teletrabalho: um estudo de caso na administração de uma instituição federal de ensino superior. 2002. Tese (Doutorado em Engenharia de sistemas e computação) - Universidade Federal do Rio de Janeiro, Rio de Janeiro, 2002.

HAU, F.; TODESCAT, M. O teletrabalho na percepção dos teletrabalhadores e seus gestores: vantagens e desvantagens em um estudo de caso. Revista de Gestão e Tecnologia, v. 8, n. 3, p. 37-52, 2018.

HAZAN, B. F.; MORATO, A. D. P. Teleworking in brazilian law: grounds, perspectives and changes promoted by labor reform. Lex Humana, v. 10, n. 1, p. 1-24, 2018.

HILL, E. J.; FERRIS, M.; MÄRTINSON, V. Does it matter where you work? A comparison of how three work venues (traditional office, virtual office, and home office) influence aspects of work and personal/family life. Journal of Vocational Behavior, v. 63, n. 2, p. 220-241, 2003.

ILLEGEMS, V.; VERBEKE, A. Telework: what does it mean for management?. Long Range Planning, v. 37, n. 4, p. 319-334, 2004.

ILLEGEMS, V.; VERBEKE, A.; S'JEGERS, R. The organizational context of teleworking implementation. Technological forecasting and social change, v. 68, n. 3, p. 275-291, 2001.

KATZ, A. I. The management, control, and evaluation of a telecommuting project: A case study. Information \& Management, v. 13, n. 4, p. 179-190, 1987.

KURLAND, N. B.; COOPER, C. D. Manager control and employee isolation in telecommuting environments. The Journal of High Technology Management Research, $\mathrm{v}$. 13, n. 1, p. 107-126, 2002. 
LEITE, A. L.; LEMOS, D. C.; SCHNEIDER, W. A. Teletrabalho: uma revisão integrativa da literatura internacional. Revista Contextus, v. 17, n. 3, p. 187-210, 2019.

LIMA, M. S. B. O teletrabalho no poder judiciário brasileiro: ganhos para tribunais e sociedade?: as experiências de Santa Catarina e Amazonas. 2018. Dissertação (Mestrado em Administração Pública) - Fundação Getúlio Vargas, Rio de Janeiro, 2018.

LODI, M. D. F.; THIOLLENT, M. J. M.; SAUERBRONN, J. F. M. Uma Discussão Acerca do Uso da Pesquisa-ação em Administração e Ciências Contábeis. Sociedade, Contabilidade e Gestão, v. 13, n. 1, 2018.

MACKE, J. A pesquisa-ação como estratégia de pesquisa participativa. In: GODOI, C. K.; BANDEIRA-DE-MELLO, R.; SILVA, A. B. Pesquisa qualitativa em estudos

organizacionais: paradigmas, estratégias e métodos. São Paulo: Saraiva, p. 217-249, 2006.

MELLO, A., et al. Teletrabalho Como Fator de Inclusão Social e Digital em Empresas de Call Center/Contact Center. Revista de Administração da Universidade Federal de Santa Maria, v. 7, n. 3, p. 373-388, 2014.

MOKHTARIAN, P. L.; SALOMON, I. Modeling the desire to telecommute: The importance of attitudinal factors in behavioral models. Transportation Research Part A: Policy and Practice, v. 31, n. 1, p. 35-50, 1997.

MROSS, H. Implantação de projeto-piloto de teletrabalho na Coordenação-Geral de Informática da Secretaria da Previdência. 2016. Trabalho de Conclusão de Curso (MBA em Administração Pública) - Escola Nacional de Administração Pública, Brasília, 2016.

NOHARA, J. J., et al. O teletrabalho na percepção dos teletrabalhadores. Innovation \& Management Review, v. 7, n. 2, p. 150-170, 2010.

PÉREZ, M. P.; SÁNCHEZ, A. M.; CARNICER, M. P. L. Benefits and barriers of telework: perception differences of human resources managers according to company's operations strategy. Technovation, v. 22, n. 12, p. 775-783, 2002.

PINTO, J. O., et al. Avaliação da viabilidade de implantação do teletrabalho no domicílio: um estudo de caso no SERPRO. 2003. Dissertação (Mestrado em Engenharia de Produção) Universidade Federal de Santa Catarina, Florianópolis, 2003.

ROCHA, C. T. M.; AMADOR, F. S. O teletrabalho: conceituação e questões para análise. Cadernos EBAPE. BR, v. 16, n. 1, p. 152-162, 2018.

ROSENFIELD, C. L.; ALVES, D. A. Autonomy and information work: telework. Dados, v. 54, n. 1, p. 207-233, 2011.

SANTA CATARINA. Universidade do Estado de Santa Catarina. Planejamento Estratégico Plano 20, de dezembro de 2010. Apresenta o planejamento estratégico da Universidade do Estado de Santa Catarina.

SCHROEDER, J. B. Impactos do teletrabalho nas atividades dos docentes do Serviço Nacional de Aprendizagem Industrial (SENAI). 2007. Dissertação (Mestrado em Administração) - Universidade Regional de Blumenau (FURB), Blumenau, 2007. 
SILVA, G. D. F. F. Perspectivas sobre o teletrabalho no contexto da administração pública brasileira: um anteprojeto. 2014. Dissertação (Mestrado em Administração Pública) - Fundação Getúlio Vargas, Rio de Janeiro, 2014.

SOLÍS, M. Moderators of telework effects on the work-family conflict and on worker performance. European Journal of Management and Business Economics, v. 26, n. 1, p. 21-34, 2017.

SULLIVAN, C.; LEWIS, S. Home-based telework, gender, and the synchronization of work and family: perspectives of teleworkers and their co-residents. Gender, Work \& Organization, v. 8, n. 2, p. 123-145, 2001.

THIOLLENT, M. Metodologia da pesquisa-ação. 17. ed. São Paulo: Cortez, 2009.

TREMBLAY, D. G. Organização e satisfação no contexto do teletrabalho. Revista de Administração de Empresas, v. 42, n. 3, p. 54-65, 2002.

TREMBLAY, D. G.; THOMSIN, L. Telework and mobile working: analysis of its benefits and drawbacks. International Journal of Work Innovation, v. 1, n. 1, p. 100-113, 2012.

TRIPP, D. Pesquisa-ação: uma introdução metodológica. Educação e pesquisa, v. 31, n. 3, p. 443-466, 2005.

VARGAS, A. V.; OSMA, J. I. P. Proposal for implementing a telecommuting model/Propuesta de implementacion de un modelo de teletrabajo. RISTI - Revista Ibérica de Sistemas e Tecnologias de Informação, n. 12, p. 17-32, 2013. 